\title{
REFLEXIONES SOBRE EL TRATAMIENTO DE LA FILIACIÓN EN EL PERÚ
}

\author{
María Isabel Sokolich Alva*
}

\section{RESUMEN}

La filiación es en "sentido genérico" la relación de una persona con todos sus antepasados, en tanto que en "sentido estricto" es la relación que vincula a los padres con los hijos; en dicho contexto, tanto en la filiación matrimonial como extramatrimonial existen cuestionamientos vinculados, de una lado, con la presunción "pater ist est quem nup tiae demonstrant", según la cual el hijo de la mujer casada tiene como padre al marido, $y$, de otro, en relación a los alcances del reconocimiento del hijo extramatrimonial y su carácter irrevocable. El presente artículo tiene por finalidad reflexionar en torno a los aspectos más relevantes de la filiación en el Perú.

Palabris Clave: Filiación, filiación matrimonial, filiación extramatrimonial.

\section{REFLECTIONS ON THE TREATMENT OF FILIATION IN PERU}

\begin{abstract}
The parentage is "generic sense" the relationship of a person with all his ancestors, while in "strict sense" is the relationship that links parents with their children; in that context, both marital and extramarital filiation there related questions, from one side, with the presumption "pater is est quem nuptiae demonstrant", whereby the child of a married woman whose husband's father, and, secondly, in relation to the scope of recognition of the illegitimate child and character irrevocable. This article aims to reflect on the most relevant aspects of descent in Peru
\end{abstract}

Key words: Family Law, filiation, extramarital filiation

\footnotetext{
* Fiscal Adjunto Supremo Titular de la Fiscalía Suprema Civil, ex Fiscal Superior Penal Titular, ex Fiscal Provincial de Familia Titular, Doctorando en Derecho, Magíster en Derecho Civil con mención en Derecho de Familia, Docente de la Maestría de Derecho Civil de la Universidad Femenina del Sagrado Corazón -UNIFE. Autora del libro "Violencia Familiar" $^{\prime \prime}$ y de diversos artículos jurídicos, expositora en diversos eventos académicos relacionados con el Derecho de Familia.

Recepción: 05-09-2012

Aceptación: 24-09-2012
} 
La familia como elemento natural y supremo de la sociedad y el Estado constantemente está sujeta a los cambios sociales, culturales, jurídicos $y$. estructurales de la sociedad, de allí que el otrora concepto de "familia nuclear" "conformada solo por padres e hijos ha cedido paso a una visión "macro" de familia, a fin de reconocerla como el conjunto de personas unidas por vínculos de parentesco (familia amplia o extendida), sin dejar de lado a aquella nueva forma de familia surgida de la recomposición familiar de sus miembros, llamada "familia ensamblada o reconstruida", que a decir del Tribunal Constitucional es "la estructura familiar originada en el matrimonio o la unión concubinaria de una pareja en la cual uno o ambos de sus integrantes tienen hijos provenientes de una relación previa"2.

La Constitución Política del Estado, en su articulo 4. consagra que "La comunidad y el Estado protegen especialmente al niño, al adolescente, a la madre y al anciano en situación de abandono. También protegen a la familia y promueven el matrimonio. Reconocen a estos últimos como institutos naturales y fundamentales de la sociedad". El máximo interprete de la Constitución ha reiterado en diversas sentencias la importancia de la familia y su protección, así como que el niño tiene derecho a tener una "familia", dada su esencia de derecho constitucional impliciro sustentado tanto en el principio-derecho de dignidad de la persona humana, como en los derechos a la vida, a la identidad, a la integridad personal, al libre desarrollo de la personalidad y al bienestar consagrados en los artículos $1^{\circ}$ y $2^{\circ}$, inciso 1) de la Norma Fundamental.

De igual forma, el máximo intérprete de la Constitución ha enfatizado losiguiente:

"(...) el disfrute mutuo de la convivencia entre padres e hijos constituye una manifestación del derecho del niño a tener una familia y no ser separado de ella, y que aun cuando los padres estén separados de sus hijos impone que la convivencia familiar deba estar garantizada, salvo que no exista un ambiente familiar de estabilidad y bienestar y que la autoridad que se le reconoce a la familia no implica que ésta pueda ejercer un control arbitrario sobre el niño, que pudiera generar un daño para su bienestar, desarrollo, estabilidad, integridad y salud ${ }^{3 \prime}$

Vale decir, que la familia es el eje del desarrollo y desenvolvimiento integral de la persona humana, de la cual surgen los vínculos de parentesco. El

2 Fundamentojurídico $8^{\circ}$ de la sentencia recaída en el Exp. No 09332-2006-PA/TC

3 Fundamentosjurídicos $5 .^{\circ}$ y $6 .^{\circ}$ de la sentencia recaída en el EXP. N..$^{\circ}$ 02892-2010-PHC/TC 
Código Civil regula 03 formas de parentesco: a) "parentesco consanguíneo", entendido como la relación familiar existente entre las personas que descienden una de otra o de un tronco común; puede ser en "línea recta", en cuyo caso el grado de parentesco se determina por el número de generaciones, $y$, en "linea colateral", el cual produce efectos civiles sólo hasta el cuarto grado; b) "parentesco por afinidad", derivado de la unión matrimonial, que vincula a cada uno de los cónyuges con los parientes consanguíneos del otro"; y, c) parentesco por adopción.

Recogiendo lo expresado por el renombrado jurista peruano Comejo Chavez ${ }^{5}$, las relaciones de parentesco resultan múltiples y variadas (hijos, nietos, bisnietos, hermanos, primos, sobrinos, cuñados, suegros, etc.); sin embargo, el parentesco más importante es el derivado de la "filiación" al relacionar a una persona con sus antepasados y descendientes, comúninente denominada "filiación genérica" y a los padres con sus hijos, que no viene a ser otra cosa que la "filiación en sentido estricto".

En doctrina, la filiación es identificada de diversas formas; así se señala que es "(...) el vinculo biológico que liga a padres con hijos"; "(..) el vínculo entre padres e hijos derivado de la relación de parentesco consanguíneo en linea recta de primer grado; "(...) en términos genéricos, la relación de una persona con todos sus antepasados y en sentido estricto, la relación que vincula a los padres con los hijos"; "(...) es el vinculo natural entre procreantes y procreados; en sentido estricto expresa la descendencia en Iinea recta y en sentido estricto es la relación inmediata del padre o la madre con el hijo".

Planiol-Ripert", afirman que "fillación" puede significar Ia descendencia en linea directa, pero en sentido juridico tiene un significado más restringido, equivalente a la "relación inmediatra del padre o madre con el hijo".

En resumen, "filiación" es en sentido estricto "el vinculo juridico que une al padre y a la madre con sus hijos, generando derechos y deberes recíprocos"; dicho vínculo desde la perspectiva de los derechos del hijo se denomina "filliación", en tanto que desde los derechos del padre o de la madre se conoce como "paternidad" o" maternidad".

\footnotetext{
4 El parentesco en la línea recta subsiste a pesar de la disolución del matrimonio, en tanto que en la línea colateral el parentesco en segundo grado se mantiene en caso de divorcio mientras viva el ex-cónyuge.

5 Cornejo Chávez, Héctor (1998). Derecho Familiar Peruano. Lima: Gaceta Jurídica.

6

PLANIOL-RIPERT (1948). Traitéélémentaire de droit civil. Paris.
} 
El ordenamiento civil vigente, inspirado en la Constitución de 1979, ${ }^{7}$ plasma el principio de igualdad de categorías de la filiación, según el cual "todos los hijos tienen igualdad de derechos frente a sus padres", desterrando de esta forma aquella clasificación de "filiación legítima" y "filiación ilegítima" en alusión al momento en que se produjo la concepción; esto es, dentro o fuera del matrimonio. En efecto, el Código Civil de 1936 regulaba en forma distinta los derechos de los hijos legítimos e ilegítimos (los que a su vez se clasificaban en naturales y no naturales), existiendo grandes diferencias en relación al nombre, el ejercicio de la patria potestad, alimentos y derechos sucesorios.

En la actualidad, el artículo $60^{\circ}$ de la Constitución Política del Estado de 1993, en lo que a filiación se refiere, reproduce literalmente el artículo $6 .^{\circ}$ de la Constitución de 1979, enfatizando, la igualdad de derechos y obligaciones de los hijos con independencia de si la concepción o el nacimiento del hijo se produjo o no durante la vigencia de un vínculo matrimonial.

Respecto de la proscripción de la mención de la naturaleza de la filiación en los Registros Civiles, es de enfatizar que por Ley n. ${ }^{\circ} 29032$, de junio de 2007, se estableció que en caso que el reconocimiento voluntario o judicial de paternidad o maternidad se haya concretado con posterioridad a la fecha de inscripción, el registrador o funcionario del Registro Nacional de Identificación y Estado Civil (Reniec) o de las Oficinas Registrales autorizadas, de oficio y en un plazo no mayor de tres días útiles de realizada la anotación de la declaración de paternidad o maternidad, está en la obligación de asentar una nueva partida o acta de nacimiento, en la cual únicamente debe consignarse como dato la referencia a la partida o acta expedida inicialmente, o, en su caso, el Código Único de Identificación otorgado al momento de la inscripción.

La finalidad de la norma es salvaguardar el derecho a la intimidad de las personas reconocidas con posterioridad al acto de inscripción ${ }^{8}$, motivo por el cual una vez asentada la nueva partida o acta de nacimiento, debe

\footnotetext{
7 Ártículo6.-El Estado ampara la paternidad responsable.

Es deber y derecho de los padres alimentar, educar y dar seguridad a sus hijos, así como los hijos tienen el deber de respetar y asistir a sus padres.

Todos los hijos tienen iguales derechos. Está prohibida toda mención sobre el estado civil de los padres y la naturaleza de la filiación de los hijos en los registros civiles y en cualquier documento de identidad.

El derecho a la intimidad personal se encuentra regulado por el numeral 7) del artículo 2. ${ }^{\circ}$ de la Constitución Política del Perú; su protección, a decir del Tribunal Constitucional, implica excluir el acceso a terceros de información relacionada con la vida privada de una persona, lo que incluye las comunicaciones, documentos o datos de tipo personal.
}

8 
expedirse, bajo responsabilidad del registrador o funcionario encargado del Registro Nacional de Identificación y Estado Civil o de las Oficinas Registrales, copia certificada de la nueva partida o acta de nacimiento, salvo que por mandato judicial se disponga lo contrario.

De otro lado, es importante acotar que la filliación se determina por naturaleza o por adopción; la primera, sea matrimonial o extramatrimonial, supone la existencia de un vínculo biológico entre el padre, la madre y al hijo; en cambio, la segunda implica la existencia de un vínculo jurídico establecido por Ley por el cual el adoptado adquiere la calidad de "hijo" del adoptante.

En alusión a la filiación matrimonial, cabe resaltar que el deber de fidelidad que se deben los cónyuges, a tenor de lo dispuesto por el artículo $280^{\circ}$ del Código Civil -que comprende el débito conyugal y la contimencia sexual-, nos podría permitir inferir prima facie que, en efecto, la presunción "pater is est quem nuptiae demonstrant" resulta válida, toda vez que de acuerdo a dicha presunción el "hijo de mujer casada tiene como padre al marido".

Empero, el avance de la ciencia demuestra que no necesariamente el "marido" de la mujer casada es el padre biológico del hijo; conforme lo expresado por Alex Plácido", el régimen de filiación del Código Civil de 1984 se sustenta en el principio del favor legitimitatis, más no siempre existe coincidencia entre la filiación legal derivada de la presunción pater ist y la realidad biológica, de allí la justificación de la ponderación de la presunción de paternidad matrimonial, la evidencia biológica de la paternidad extramatrimonial y el interés superior del hijo a su real identidad.

Es indiscutible que la prueba de $\mathrm{ADN}$ ha contribuido en forma significativa a esclarecer la paternidad, y, por ende, la filiación del hijo, y con ello garantizar su derecho a la identidad; no obstante, todo estudio o

Por el fundamento jurídico $38 .^{\circ}$ de la sentencia recaida en el Exp. $n .{ }^{\circ} 6712-2005-\mathrm{HC}$, se señaló lo siguiente: "(...) cos respecto al bien jurídico tutelado en la Constitución, no cabe duda que la vida privada refleja uno de muy dificil comprensión, tanto asi que algunos consideran que se trata de un concepto juridico indeterninado. No obstanie ello, juzgamos que es necesario plantearse sobre él un concepto inicial y preliminar.

Son diversas las posturas para explicar el significado de la vida privada. Algunas la conciben como aquella zona de la persona que no es pública, por lo que nadie debe tener acceso a ella. Sin embargo, más correcto es tratar de utorgar un sentido positivo. Así (...) se ha estimado apropiado afirmar que es el ámbito personal en el cual un ser humano tiene la capacidad de desarrollar y fomentar libremente su personalidad. Por ende, se considera que está constituida por los datos, hechos o situaciones desconocidos para la comunidad que, siendo veridicos, están reservados al conocimiento del suieto mismo y de un grupo reducido depersonas, y cuya divulgación o conocimiento por otros trae aparejado algún daíio". 
cuestionamiento de la filiación matrimonial o extramatrimonial siempre confronta 02 derechos: a) el derecho de los padres a su intimidad, y, b) el derecho del hijo a conocer y gozar de su verdadera identidad.

En cuanto al derecho de las personas a su intimidad el Tribunal Constitucional ha señaladolo siguiente:

\> (...) a través de su jurisprudencia este Tribunal Constitucional ha determinado los alcances del derecho a la intimidad (Cfr. STC N. ${ }^{\circ}$ 06712-2005-HC, caso Magaly Medina, fundamento 38): "Con respecto al bien jurídico tutelado en la Constitución, no cabe duda que la vida privada refleja uno de muy difícil comprensión, tanto así que algunos consideran que se trata de un concepto jurídico indeterminado. No obstante ello, juzgamos que es necesario plantearse sobre él un concepto inicial y preliminar. Son diversas las posturas para explicar el significado de la vida privada. Algunas la conciben como aquella zona de la persona que no es pública, por lo que nadie debe tener acceso a ella. Sin embargo, más correcto es tratar de otorgar un sentidc jositivo. Así (...) se ha estimado apropiado afirmar que es el ámbito personal en el cual un ser humano tiene la capacidad de desarrollar y fomentar libremente su personalidad. Por ende, se considera que está constituida por los datos, hechos o situaciones desconocidos para la comunidad que, siendo veridicos, están reservados al conocimiento del sujeto mismo y de un grupo reducido de personas, y cuya divulgación o conocimiento por otros trae aparejado algún daño". En consecuencia, la protección de la intimidad implica excluir a terceros extraños el acceso a información relacionada con la vida privada de una persona"10

En lo atinente a la filiación, la prueba de Ácido desoxirribonucleico (ADN) ha contrastado la filiación legal con la verdad biológica, trayendo abajo la presunción pater ist y el reconocimiento del hijo extramatrimonial efectuado en merito a la creencia de paternidad.

De acuerdo al estudio efectuado por Celeste Cecilia Mels Siningen ${ }^{11}$, el ADN contenido en todas las células de cada persona es transmitido de los padres a los hijos de generación en generación, una sola cadena de nuestro ADN (localizado en nuestras células) contiene muchos genes. Todos estos genes son necesarios para construir cada uno de los órganos de nuestro cuerpo (corazón, hígado, estomago, pulmones, ojos, etc.) y hacerlos funcionar. En ciertos puntos de nuestra secuencia de ADN, existen piezas de

\footnotetext{
${ }^{10}$ Fundamento jurídico $11 .^{\circ}$ de la sentencia recaída en EXP.N. ${ }^{\circ} 05982-2009-P H D / T C$

11 http://www.biotech.bioetica.org
} 
ADN que varian de persona a persona. Aunque cuando todos somos similares, el ADN que heredamos de nuestros padres nunca se combina de la misma manera, estas variaciones individuales en la secuencia del ADN, son lo que nos hace, a nivel genético, diferentes el uno del otro.

Como sabemos los resultados obtenidos luego de una prueba de ADN permiten lograr una confiabilidad del 99,99\% como mínimo en el caso de una inclusión de paternidad y de un $100 \%$ en caso de exclusión.

En la actualidad en el país rige la Ley n. ${ }^{\circ} 28457$, modificada por Ley $n .{ }^{\circ}$ 29821, que regula el proceso de filiación judicial de paternidad extramatrimonial, cuya finalidad desde un inicio ha sido solurionar prontamente la problemática de los niños no reconocidos a fin de asegurarles tanto su derecho a la identidad como los derivados de la relación paterno filial.

La esencia del proceso, en caso de mediar oposición por parte del emplazado, es la actuación de la prueba biológica del ADN con muestras del padre, la madre y el hijo. El Juez por el solo mérito del resultado de la prueba biológica del ADN resuelve la causa ${ }^{12}$. Es importante resaltar que la modificación legislativa introduce la posibilidad de acumular a la pretensión principal, como pretensión accesoria, la fijación de una pensión alimentaria a favor del hijo, la cual dada su estrecha relación con la pretensión principal coadyuva a satisfacer en forma integral las necesidades inmediatas del hijo.

Cabe enfatizar, que el Código Civil prescribe que los únicos medios de probar la filiación extramatrimonial son el reconocimiento y la sentencia declaratoria de la paternidad o la maternidad; el primero, sujeto a la voluntad del reconociente, $y$, el segundo, consecuencia de la valoración positiva del caudal probatorio aportado al proceso de declaración judicial de paternidad extramatrimonial.

Una de las interrogantes que surge en relación a esto último es la siguiente: ¿en caso de colisionar el debido proceso con el derecho a la identidad cuál debe prevalecer?

La sentencia expedida por el Tribunal Constitucional, con fecha 17 de setiembre de 2010, en el EXP. N. ${ }^{\circ} 00550-2008-P A / T C$, resulta ilustrativa en relación al tema, toda vez que luego de valorarse el derecho a la identidad y el

\footnotetext{
12

2 Declara fundada la oposición, en caso que la prueba produjera un resultado negativo, o, infundada la oposición, en cuyo caso el mandato se convertirá en declaración judicial de paternidad y el emplazado será condenado a las costas y costos del proceso.
} 
interés superior del niño frente a la inmutabilidad que le asiste a la cosa juzgada -garantía constitucional del debido proceso-, se privilegia lo primero.

Dicha sentencia hace énfasis en los siguientes aspectos:

1) Toda sentencia firme que pone fin al proceso seguido entre los mismos sujetos procesales con pronunciamiento sobre los mismos hechos tiene la calidad de cosa juzgada; empero, el fallo dictado en el proceso sobre filiación extramatrimonial incoado por doña Regina Pilco Ayala con el objeto de que don René Quenta Calderón reconociera como hijo al adolescente Héctor José Pilco, si bien finaliza el conflicto de intereses de los progenitores, no resuelve el problema del adolescente que por su condición de persona humana constituye el fin supremo de la sociedad y del Estado y goza de una especial protección conforme lo disponen la Constitución y el Derecho Internacional de los Derechos Humanos, teniendo, por tanto, derecho a su identidad.

2) En el caso concreto, es innegable que en el proceso sobre filiación extramatrimonial (Exp. No 150-95) y en el proceso de filiación judicial de paternidad extramatrimonial (Exp. N. ${ }^{\circ}$ 2005-1416), entablados por doña Regina Pilco Ayala, concurren todos los elementos que configuran la triple identidad a que se refiere el artículo $452 .^{\circ}$ del Código Procesal Civi1 ${ }^{13}$, no obstante, al existir nuevas formas de acreditar la pretensión como la prueba de ADN que no existía cuando se archivó el primer proceso, es atendible priorizar el derecho a la identidad y el interés superior del niño frente a la inmutabilidad que le asiste a la cosa juzgada.

3) Debe ponderarse que de un lado se tiene el derecho del adolescente que pretende conocer a su progenitor y llevar su apellido, $y$, de otro el derecho del padre a que se respete la inalterabilidad y definitividad que le asiste al fallo expedido en un proceso anterior.

4) Si bien la cosa juzgada es importante, esta institución no puede superponerse al derecho a la identidad reclamado por el adolescente, más aún la especial protección que regula el artículo $4 . .^{\circ}$ de la Norma

13 Artículo 452.- Hay identidad de procesos cuando las partes o quienes de ellos deriven sus derechos, el petitorio y el interés para obrar, sean los mismos. 
Fundamental, que impone al Estado el deber de adoptar las medidas correspondientes para garantizar el bienestar físico, psíquico, moral, intelectual, espiritual y social de la persona, siendo inevitable la incidencia sobre el proyecto de vida, cuando no se descarta o establece a cabalidad el vínculo parental entre una persona y su presunto progenitor.

Finalmente, respecto de la responsabilidad de los operadores de justicia en los procesos de filiación, resulta importante destacar que la Corte Suprema de Justicia del Perú por el III Pleno Casatorio Civil recaído en la Casación $N^{\circ}$ 4664-2010 PUNO, ha establecido como precedente judicial vinculante lo siguiente:

$\gg$ "En los procesos de familia, como en los de alimentos, divorcio, filiación, violencia familiar, entre otros, el Juez tiene facultades tuitivas y en consecuencia debe flexibilizar algunos principios y normas procesales como los de iniciativa de parte, congruencia, formalidad, eventualidad, preclusión, acumulación de pretensiones, en atención a la naturaleza de los conflictos que debe solucionar, derivados de las relaciones familiares y personales, ofreciendo protección a la parte perjudicada, de conformidad con lo dispuesto en los artículos $40^{\circ}$ y $430^{\circ}$ de la Constitución Política del Estado" (lo subrayado es nuestro).

Flexibilizar, implica, que el Juez que conoce un proceso en el cual se encuentra involucrado un niño, más aún si de establecer su filiación se trata, debe internalizar que el caso sometido a su conocimiento es un "problema humano" y que, por ende, merece especial atención y consideración; en ese sentido, los procesos no pueden estar sujetos a normas procesales estrictas o trabas que impidan administrar justicia, más aún el rol tuitivo que corresponde al juzgador.

Debemos resaltar, que la obligación de la comunidad y el Estado de proteger especialmente al niño, niña y adolescente tiene como sustento el reconocimiento del Principio del Interés Superior del Niño, el cual se antepone a cualquier otro derecho o interés en controversia, además de constituir una norma sustantiva que tienen prevalencia sobre cualquier norma procesal. 


\section{REFERENCIAS}

Cornejo Chávez, Héctor (1998). Derecho Familiar Peruano. Lima: Gaceta Jurídica.

Planiol-Ripert (1948). Traité élémentaire de droit civil. Paris: Librairie Générale de Droit et De Jurisprudence.

Plácido V., Alex (2008). La evidencia biológica y la presunción de paternidad matrimonial. Lima: Fondo Editorial de la PUCP.

Mels Siningen, Celeste Cecilia: ADN en la Prueba de Filiación En: Regulación Jurídica de las Biotecnologías (On line). Disponible en Internet http://www.biotech.bioetica.org/i28.htm, consultado el 22 de septiembre de 2012. 